\title{
PROMOTING BASIC COGNITIVE SKILLS THROUGH CONSTRUCTIVIST-BASED STRATEGIES IN A PHYSIOLOGY COURSE
}

\author{
Francisca Mendoza, Martha Gaeta, Virginia Sedeño \\ Universidad Popular Autónoma del Estado de Puebla, México \\ E-mail: franciscamaria.mendoza@upaep.mx, marthaleticia.gaeta@upaep.mx, \\ virginia.sedeno@upaep.mx
}

\begin{abstract}
One of the main purposes of education today is to develop student's ability to think in a systemic, analytical and logical manner to become self-directed, critical thinkers. Hence, students need to be efficient in one or more basic cognitive skills (BCS), since they are the foundational skills for the continued growth of these and other intellectual higher level abilities. According to constructivist theorists, the development of students deep conceptual understanding takes place when they are engaged in learning tasks that explicitly makes them aware of their BCS, based on students' previous knowledge and matter content. From this perspective, teachers can promote BCS in the classroom through the design of constructivist-based strategies. Therefore, the main purpose of the present study was to examine how the BCS of analysis and synthesis are attained in a university physiology course, examining differences in two groups of students from different classes using different learning methods: problem-based learning (PBL) and PBL plus diagrams. A self-report questionnaire was designed for this purpose. A knowledge exam was also applied to both groups at the end of the intervention to evaluate students' basic knowledge attainment. Results indicate that there were no significant differences between the two groups in their BCS acquisition. Exam scores were not different between groups either. However, a significant relationship between BCS and basic knowledge attainment was found. Results are discussed in more detail within the document.
\end{abstract}

Key words: basic knowledge, cognitive skills, constructivism, problem based learning

\section{Introduction}

University medical students must develop specific competencies that enable them to solve and prevent health problems in contexts where mental processes are needed. One of the main abilities is "the acquisition of the scientific basis of Medicine", which is achieved through the development of BCS such as organization, analysis and synthesis of existing knowledge and new matter content, that allow students to make valid inferences and judgments and to determine the interactions on organizational system levels (from molecular to biopsychosocial) (Abreu et al., 2008). Accordingly, one of the main purposes of the physiology course is to provide students with the scientific basis that the medical profession requires and to help them to develop systemic thinking, through the promotion of BCS.

Traditionally, physiology has been taught through classic readings and laboratory practices, with little emphasis on strengthening the specific competencies that the future medic requires (Gal, Basturia \& Garrido, 2011). Education today demands reforms focused on an integrated curricula, where students have a more active role in the construction of their knowledge (Esprívalo, 2010; Venville, Rennie \& Wallace, 2009). Therefore, teaching strategies that promote student-centered learning are required in physiology courses, as an alternative to the traditional instructional methods (Anyaehieet al., 2010). This involves the use of constructivist- 
Francisca MENDOZA, Martha GAETA, Virginia SEDEÑO. Promoting Basic Cognitive Skills through Constructivist-based Strategies in a Physiology Course

EMMS

OF EDUCATION

IN THE $21^{\text {st }}$ CENTURY

Volume 54, 2013

based strategies and new evaluation methods for the development of BCS (Díaz, 2006) and the assessment of all the different aspects of knowledge attainment (Gal et al., 2011).

Problem-based learning (PBL) is a student centered method focusing on learners' active production of knowledge, in accordance with the development of their abilities and attitudes, through engaging with real world cases (Tambouris et al., 2012). Also, PBL is a flexible method that can be implemented in different subjects and disciplines (Savin-Baden, 2001 in Kolmos et al., 2007). Research has shown that PBL helps students to stimulate their motivation and learning interest, which in turn helps them to achieve significant learning (Abraham, Vinod, \& Kamath, 2008). Specifically, medical students trained in PBL have shown a good performance in clinical evaluations (diagnosis and planning treatment), as well as an improvement in problem formulation and more autonomous behavior (Albanese \& Mitchell, 1993). However, they have shown deficiencies in building their knowledge base (De Graaff and Kolmos, 2003 in Kolmos et al., 2007; Albanese \& Mitchell, 1993).

As it as been mentioned before, BCS favor knowledge acquisition and are essential for all mental activities (Diaz, 2006; Selvaratnam, 2011), since they are the foundational skills for the continued growth of these and other intellectual higher level skills that students learn in university, at work and in life. However, these higher level skills will be compromised if any of the BCS are inefficient. For example, if students are inefficient at analysis and synthesis, then they will not be good at physiology as it is built on the ability to analyze and synthesize.

From this perspective, PBL may work better when used in conjunction with conventional methods (Benson, 2012). Different studies in learning attainment indicate that content diagrams favor the construction of knowledge schemes about the content of a text, allowing students to identify rhetoric relations present and helping them to locate or infer the most important information (Doguis, 2001). Therefore, the main purpose of this work was to investigate students' development of BCS (of analysis and synthesis) for basic knowledge acquisition in physiology, by using two different learning strategies (PBL and PBL plus diagrams).

\section{Methodology of Research}

\section{Sample}

The participants were comprised of 47 students ( $51 \%$ women and $49 \%$ men) from two physiology classes of the medical school at a university in central Mexico.

\section{Design}

The study employed a quasi-experimental design with two intact groups, consisting of two whole physiology classes which were chosen out of the total ten physiology groups at the university. Two research tools were used: the first group (21 students) worked with the PBL strategy and the second group (26 students) worked with the hybrid strategy (PBL plus diagrams).

Students in both groups shared some common characteristics; all of them were in their first year at university and the students' academic performance (grade point average) at the beginning of the academic term was not significantly different between groups, $(t=0.48 ; \mathrm{p}=0.63)$, therefore they were considered equivalent. Results on the samples' distribution, measured by the Kolmogorov-Smirnov test, showed that both groups presented a normal distribution (variance $=0.82 ; \mathrm{p}=0.2$ ). A final physiology exam (postest) was administered at the end of the academic term to assess differences between groups. 
Francisca MENDOZA, Martha GAETA, Virginia SEDEÑO. Promoting Basic Cognitive Skills through Constructivist-based Strategies in a Physiology Course

\section{Instrument and Procedures}

In order to evaluate students' BCS acquisition, a self-report questionnaire designed for this study was applied. The scale comprised 20 items divided in two sections, analysis and synthesis: In both BCS groups three aspects were studied: a) structures, b) relations and c) functions. The participants evaluated statements on BCS along a four-point Likert scale: (4) totally agree; (3) agree; (2) disagree; and (1) totally disagree. The instrument's reliability level (Cronbach's alpha) is 0.91 .

Students' basic knowledge attainment was estimated through a final physiology exam administered during the last class session for both groups.

An informed consent was given to the students. The data were collected in both participant groups throughout a whole academic period (four months), during the regular physiology schedule (seven hours per week), under the supervision of the class teacher. Depending on the dynamic of each group, students were asked to hand in at the end of the course: 1) A report of all solved problems (both groups), 2) elaborated diagrams of the physiology contents (group 1 during all the course and group 2 only one at the end of the course).

\section{Data Analysis}

Differences between the two groups were assessed by means of the Student t-test. The correlation between BCS and basic knowledge attainment was analysed through the Pearson coefficient. The statistical analyses were carried out using the SPSS statistical program.

\section{Results of Research}

\section{Differences in BCS between Groups with Different Learning Strategies}

According to Student t-test there were no significant differences between both groups in BCS $(t=1.48 ; p=0.07)$. In group 1 (PBL) all BCS values were distributed between quartiles 25 and 68, while in group 2 (PBL plus diagrams), BCS values were located between quartiles 38 and 72 (see Figure 1). 
Francisca MENDOZA, Martha GAETA, Virginia SEDEÑO. Promoting Basic Cognitive Skills through Constructivist-based Strategies in a Physiology Course

PROBLEMS

OF EDUCATION

IN THE $21^{\text {st }}$ CENTURY

Volume 54, 2013

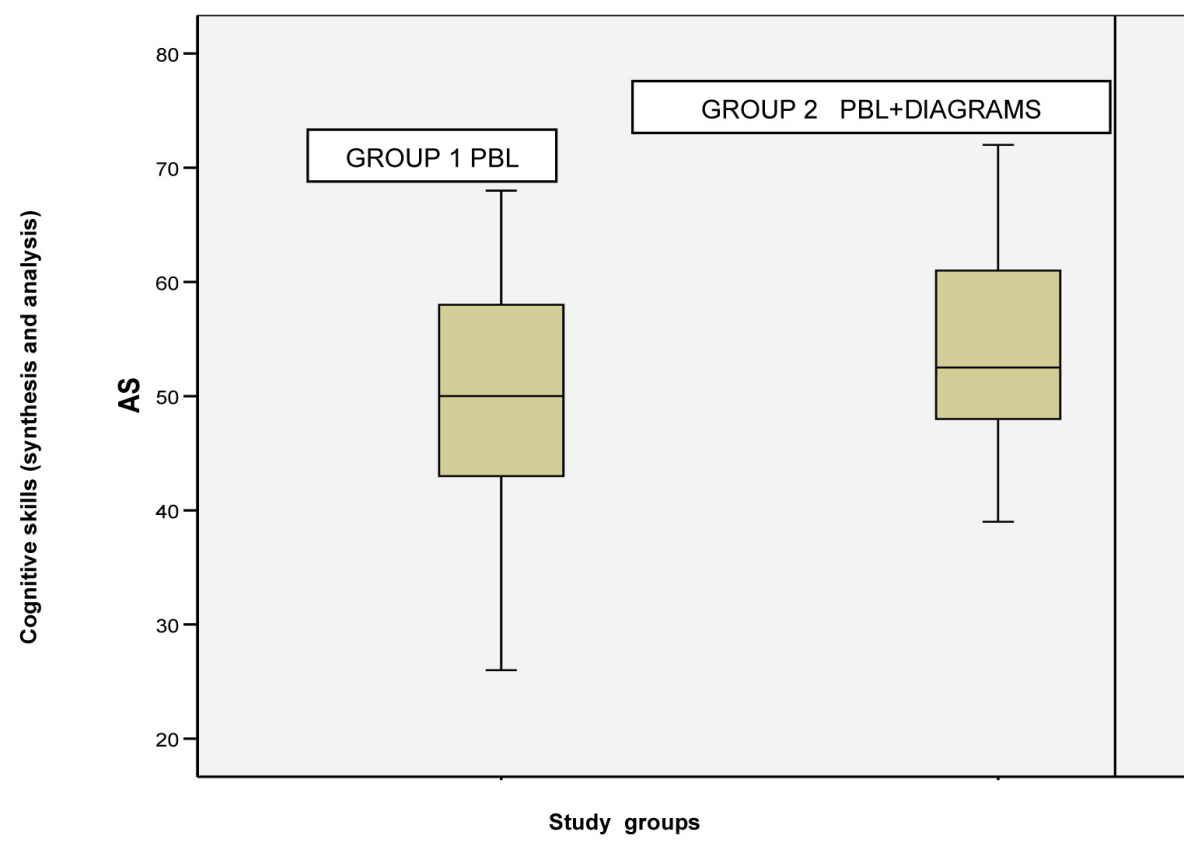

Figure 1: Differences in BCS between groups with different learning strategies: PBL and PBL plus diagrams.

Differences in Basic Knowledge Attainment between Groups with Different Learning Strategies

Regarding the comparative analysis of basic knowledge attainment between groups, as shown in Figure 2, there was not a significant difference between both groups $(\mathrm{t}=0.58 ; \mathrm{p}=0.28)$. In group 1 (PBL) quartiles 3 and 4 were located between 6.5 and 9.3, while in group 2 (PBL plus diagrams), quartiles 3 and 4 were placed between 6.5 and 8.4.

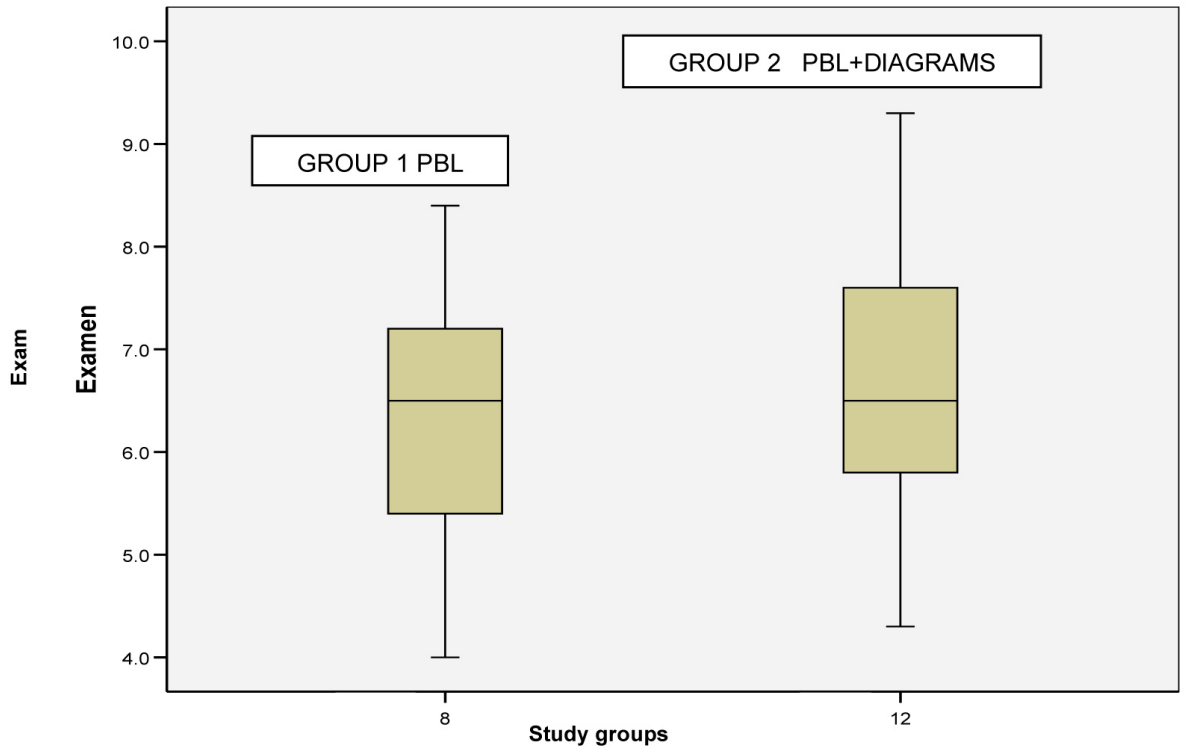

Figure 2: Differences in the basic knowledge attainment between groups with different learning strategies: PBL and PBL plus diagrams. 
To analyze the relationship between BCS and basic knowledge attainment, the Pearson coefficient correlation was used. A significant correlation between both variables was found $(\mathrm{r}=0.75 ; \mathrm{p}<0.001)$ (see Figure 3$)$.

When analyzing the correlations between the three aspects of analysis (structures, functions and relations) and basic knowledge attainment, it was found that analysis of relations was the most related variable $(\mathrm{r}=0.73 ; \mathrm{p}<0.001)$, followed by analysis of functions $(\mathrm{r}=0.64$; $\mathrm{p}<0.001)$ and analysis of structures $(0.36, \mathrm{p}<0.05)$.

Regarding the correlations between the three aspects of the synthesis (structures, functions and relations) and basic knowledge attainment, synthesis of relations was the most related variable $(r=0.63, p<0.001)$, followed by the synthesis of functions $(r=0.54, p<0.001)$ synthesis of structures $(0.30, \mathrm{p}<0.05)$.

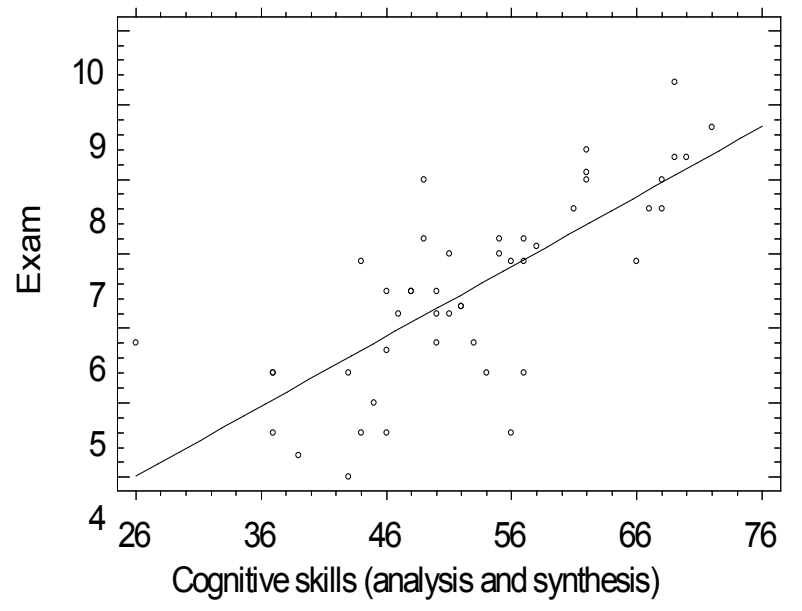

Figure 3: Relationship between BCS and basic knowledge attainment.

\section{Discussion}

A quasi-experimental study was designed to compare university medical students' development of BCS in a physiology course through two different learning strategies, namely PBL and PBL plus diagrams, and to see how these strategies also relate to their basic knowledge attainment.

Results show that there are no statistically significant differences in BCS acquisition in the group working with PBL and the group working with PBL plus diagrams. According to Benson (2012) PBL may work better when used in conjunction with conventional methods. However, the present study result shows that using diagrams besides PBL doesn't promote BCS to a greater extent. Moreover, there are no statistically significant differences between both groups in basic knowledge attainment. Nevertheless, both groups of students developed adequate levels of these variables, reflecting that PBL is an adequate method for the discovery of knowledge and skills in the subject (Abraham et al., 2008) and the use of diagrams is just a part of this constructivist-based method. This finding leads us to future research with a larger sample and using other additional strategies in order to confirm these results.

Benson (2012) recommends the use of PBL as a complementary method for student academic performance, especially in undergraduate scenarios. Accordingly, a study with university students in Turkey (Kuru in Kolmos et al., 2007) found that students developed analysis and synthesis and design skills in the course through case study, lecture and project work. There- 
Francisca MENDOZA, Martha GAETA, Virginia SEDEÑO. Promoting Basic Cognitive Skills through Constructivist-based Strategies in a Physiology Course

EMS

OF EDUCATION

IN THE $21^{\text {st }}$ CENTURY

Volume 54, 2013

fore, PBL combined with different strategies should be used by the students, since physiology is a complex subject that requires comprehension of biology, biochemistry, anatomy, histology, chemistry and physics knowledge, which needs an integrative capability (Sefton, 2005); if students acquire an adequate strategy for them to physiology understanding, they may have an improvement with respect to compulsory subjects along their academic studies. In addition, further evaluations should include both qualitative and quantitative approaches.

About the relation between BCS and basic knowledge attainment, a statistically significant correlation between both variables was found. Specifically, in both BCS (analysis and synthesis) the three aspects considered (structures, functions and relations) are significantly related to students' knowledge acquisition. These results are consistent with the literature (Tambouris et al., 2012), showing that BCS favor knowledge acquisition; this is very important for successful learning, since it contributes to the development of the ability to learn and make sense of new information, based on previous knowledge, allowing students to make valid inferences and judgments and to determine the interactions on organizational system levels (from molecular to biopsychosocial) (Abreu et al., 2008).

\section{Conclusions}

This study provides evidence on BCS acquisition for the development of knowledge base, through PBL, in university medical students. As it as been mentioned before, one of the main purposes of the physiology course is to provide students with the scientific basis that the medical profession requires and to help them to develop systemic thinking, through the promotion of BCS. Therefore, the teaching and learning emphasis must be on promoting students' acquisition of content knowledge as well as on training them in intellectual abilities, through the use of constructivist-based strategies, such as PBL and new evaluation methods, to ensure that students become more competent in basic knowledge attainment.

Teachers can contribute to students' development of BCS by using PBL and other relevant and varied resources, such as: integration of BCS with subject content knowledge during compulsory courses, combination of case study, lecture and project work and the inclusion of questions on BCS in examination papers, which will help students to be aware of their BCS and to improve these and other higher-level skills for the promotion of their systemic, analytical, logical, critical thinking.

\section{Acknowledgements}

The authors acknowledge the valuable contribution of MSc José Luis Avila, MD Francisca Castellanos and MSc Uxmal Rodríguez.

\section{References}

Abraham, R., Vinod, P., \& Kamath, M. G. (2008). Learning approaches of undergraduate medical students to physiology in a non-PBL- and partially PBL oriented curriculum. Advanced Physiology Education Journal, 32, 35-37.

Abreu, H. L., Cid, G. A., Herrera, C. G., Lara V. J., Laviada, D. R., Rodríguez, A. C., \& Sánchez, A. J. (2008). Perfil por Competencias del Médico General Mexicano. Asociación Mexicana de Facultades y Escuelas de Medicina (AMFEM). México: Elsevier. Masson Doyma.

Albanese, M. A., \& Mitchel, S. (1993). Problem-based learning: a review of literature on its outcomes and implementation issues. Academic Medicine, 68 (1), 52-81.

Anyaehie, U. S., Nwobodo, E., Oze, G., Nwagha, U. I., Orizu, I., Okeke, T., \& Anyanwu, G. E. (2010). Medical students' evaluation of physiology learning environments in two Nigerian medical schools. Advances in Physiology Education, 35, 146-148. 
Francisca MENDOZA, Martha GAETA, Virginia SEDEÑO. Promoting Basic Cognitive Skills through Constructivist-based Strategies in a Physiology Course

Benson, S. (2012). The relative merits of PBL (Problem-Based Learning) in university education. US-

PROBLEMS

OF EDUCATION

IN THE $21^{\text {st }}$ CENTURY

Volume 54, 2013

China Education Review A. 4, 424-430.

Díaz, F. (2006). Enseñanza Situada. Vínculo entre la escuela y la vida. México: McGraw-Hill.

Doguis, P. G., (2001). Efectos de diagramas de contenido en la comprensión y retención de textos. Docencia Universitaria, 2 (2), 7. Retrieved from: http://www.ucv.ve/fileadmin/user_upload/sadpro/ Documentos/docencia_vol2_n2_2001/8_art._5Gloria_Doguis.pdf

Esprívalo, P. (2010). Teaching an Integrated Science Curriculum: Linking Teacher Knowledge and Teaching Assignments. Issues in Teacher Education, 19 (1), 145-165.

Gal, B., Busturia, I., \& Garrido, C. (2011). To be or not to be: the importance of attendance in integrated physiology teaching using non-traditional approaches. BMC Research Notes, 4. Retrieved from: http://www.biomedcentral.com/1756-0500/4/360

Kolmos, A., Kuru, S., Hansen, H., Eskil, T., Podesta, L., Fink, F., De Graaff, E., Wolff, J., \& Soylu, A. (2007). Problem Based Learning. TREE - Teaching and Research in Engineering in Europe. Retrieved 3/02/2013, from: http://www.unifi.it/tree/dl/oc/b5.pdf

Savin-Baden, M. (2001). The problem based learning landscape. Planet-Special Edition 2 (November), 4-6. Retrieved 3/02/13, from: http://journals.heacademy.ac.uk/doi/pdfplus/10.11120/ plan.2001.00040004

Sefton, A. (2005). Charting a global future for education in physiology. Advanced Physiology Education Journal, 29, 189-193.

Selvaratnam, M. (2011). High School Physical Sciences Teachers Competence in Some Basic Cognitive Skills. South African Journal of Chemistry, 64, 231-236.

Tambouris, E., Panopoulou, E., Tarabanis, K., Ryberg, T., Buus, L., Peristeras, V., Lee, D., \& Porwol, L. (2012). Enabling Problem Based Learning through Web 2.0. Educational Technology and Society, 15 (4), 238-251.

Venville, G., Rennie, L. \& Wallace, J. (2009). Disciplinary versus Integrated Curriculum: The challenge for school science. The New Critic, 10. Retrieved 16/05/13, from: http://www.ias.uwa.edu.au/ new-critic

Advised by Milan Kubiatko, Masaryk University, Czech Republic

Received: May 07, 2013

Accepted: May 30, 2013

Francisca Mendoza Master in Physiological Sciences, Professor at the Department of Biological Sciences, Universidad Popular Autónoma del Estado de Puebla, 21 Sur 1103, Col. Santiago, 72410 Puebla, México.

E-mail: franciscamaria.mendoza@upaep.mx

Martha Gaeta Professor-Researcher, Universidad Popular Autónoma del Estado de Puebla, México.

E-mail: marthaleticia.gaeta@upaep.mx

Virginia Sedeño

Professor-Researcher at the Department of Health Sciences, Universidad Popular Autónoma del Estado de Puebla, México.

E-mail: virginia.sedeno@upaep.mx 